\title{
Efeitos clínicos e microbiológicos do óleo de copaíba (Copaifera officinalis) sobre bactérias formadoras de placa dental em cães
}

\author{
[Clinical and microbiological effects of copaiba oil (Copaifera officinalis) on dental plaque \\ forming bacteria in $\left.\operatorname{dog}_{s}\right]$ \\ F.A. Pieri ${ }^{1}$, M.C. Mussi ${ }^{2}$, J.E. Fiorini ${ }^{3}$, J.M. Schneedorf ${ }^{4}$ \\ ${ }^{1}$ Universidade Federal de Viçosa \\ R. P.H. Rolfs, s/n \\ 36571-000 - Viçosa, MG \\ ${ }^{2}$ Universidade de São Paulo - São Paulo, SP \\ ${ }^{3}$ Unifenas - Alfenas, MG \\ ${ }^{4}$ Unifal-MG - Alfenas, MG
}

\begin{abstract}
RESUMO
O potencial de uso do óleo de copaíba (Copaifera officinalis) na prevenção da doença periodontal, eliminando seu agente etiológico, foi avaliado em 18 cães sem raça definida, distribuídos homogeneamente em três grupos: teste, (contendo óleo de copaíba) controle positivo e controle negativo. Os tratamentos ocorreram três vezes ao dia, durante oito dias. Ao nono dia, os animais receberam aplicação tópica de fucsina básica $0,5 \%$ para evidenciação do biofilme. Mudanças na halitose e gengivite foram avaliadas diariamente por inspeção visual. Adicionalmente, foram realizados testes laboratoriais de inibição de aderência de Streptococcus mutans e ensaio antimicrobiano de difusão em ágar, sobre bactérias formadoras de placa dental. Os resultados da placa evidenciada apontaram áreas de cobertura microbiana nos dentes de $53,4 \pm 8,8 \%, 28,5 \pm 5,4 \%$, e $22,3 \pm 5,3 \%$ para os grupos negativo, positivo e teste, respectivamente, indicando diferença entre o controle negativo e os demais grupos $(\mathrm{P}<0,05)$. Quanto à melhora nos aspectos clínicos, halitose e gengivite, o grupo teste respondeu melhor quando comparado ao grupo controle negativo $(\mathrm{P}<0,05)$. A análise dos ensaios de difusão e inibição de aderência mostrou superioridade do grupo da copaíba (teste) em relação aos outros grupos $(\mathrm{P}<0,05)$. Os resultados sugerem o uso do óleo de copaíba na prevenção da doença periodontal e como um possível substituto da clorexidina na terapia antimicrobiana oral.
\end{abstract}

Palavras-chave: cão, gengivite, placa dentária, odontologia preventiva

\begin{abstract}
The copaiba oil (Copaifera officinalis) potential was evaluated in preventing periodontal disease and reducing its etiology. For that 18 mongrel dogs were homogeneously distributed in three groups: test (copaiba oil), positive control (chlorexidine) and negative control. The treatments were carried out three times a day, during eight days. On the $9^{\text {th }}$ day, the animals were tested with a $0.5 \%$ basic solution of fuchsin for the detection of biofilm. Changes in halitosis and gingivitis were daily observed. In addition, the following laboratory tests were done: inhibition of the adherence of Streptococcus mutans, and plaque forming bacteria antimicrobial assays by the agar diffusion method. The results of the fuchsin test showed that dental plaque reached areas of $53.4 \pm 8.8 \%, 28.5 \pm 5.4 \%$, and $22.3 \pm 5.3 \%$ in the negative control, positive control, and test groups, respectively, showing differences between dogs from the negative control group and dogs from the other two groups $(P<0.05)$. Furthermore, halitosis and gingivitis decreased in the copaiba group animals when compared with the negative group $(P<0.05)$. The results of the attachment inhibition and agar diffusion tests showed that copaiba induced better effects against the microorganisms as compared to the results of the other groups $(P<0.05)$. These findings suggest that copaiba oil may effectively replace chlorexidine for oral antimicrobial therapy and prevention of periodontal disease.
\end{abstract}

Keywords: dog, gingivitis, dental plaque, preventive dentistry

Recebido em 24 de setembro de 2009

Aceito em 10 de junho de 2010

Email: fabio.pieri@ufv.br 


\section{INTRODUÇÃO}

A doença periodontal, patologia que atinge o periodonto, tem sido relatada como a afecção patológica que mais acomete os cães, com prevalência de até $85 \%$ em animais acima de quatro anos. (De Marco e Gioso, 1997).

O acúmulo de bactérias supragengivais na face dental é responsável pelo desenvolvimento de uma reação inflamatória ao redor da gengiva, o que é considerado o ponto de partida da doença periodontal (Hennet, 2002; Brown e McGenity, 2005). Os principais microrganismos envolvidos na formação da placa dentária são, em sua maioria, cocos Gram-positivos aeróbios (Sans e Newman, 1997). É relatado, como um dos principais gêneros envolvidos na formação da placa inicial, o gênero Streptococcus, com especial referência à espécie $S$. mutans. Essa importante participação na formação da placa inicial relaciona o gênero Streptococcus diretamente com a etiologia da doença periodontal (Katsura et al., 2001). Como sinais clínicos importantes, relacionados à instalação da doença periodontal, citam-se a inflamação gengival, em que a gengiva apresenta-se com coloração alterada, mais vermelha, e a halitose, caracterizada como odor desagradável na cavidade oral (De Marco e Gioso, 1997).

Como alternativa no combate à placa bacteriana inclui-se, na estratégia terapêutica, o uso de substâncias com atividade antimicrobiana, que podem ser administradas ao paciente por via oral, no caso dos sistêmicos (Clarke, 2001), ou por aplicação direta nos dentes e nas estruturas orais (Hennet, 2002), ou acrescentadas na composição de alimentos e petiscos para animais de estimação (Brown e McGenity, 2005). Na terapêutica da doença periodontal, a clorexidina é a substância que tem sido utilizada em maior escala pelos profissionais, tanto na odontologia veterinária quanto na humana (Gioso, 2003). Porém, seu uso tem sido restrito a poucos dias, devido a efeitos indesejáveis, como perda de paladar, escurecimento do esmalte dos dentes, ardência e até ulcerações da mucosa jugal (Zanini et al., 1995). Dessa forma, seu uso é contraindicado para tratamentos prolongados, o que o inviabiliza como agente quimioterápico preventivo da doença periodontal (Lascala e Moussalli, 1995). Nesse ínterim, têm-se procurado novos produtos para utilização na prevenção da doença por meio de inibição da placa bacteriana (Harvey et al., 1995). Tais produtos devem possuir características específicas, como inibição do crescimento bacteriano e inibição da aderência dos microrganismos à superfície dental (Sudo et al., 1976).

A medicina tradicional tem servido como grande fonte de compostos alternativos para o uso na terapêutica de diversas doenças. Tem-se destacado, entre os produtos naturais no Brasil, a copaíba (Copaifera sp.), árvore de grande porte, que pode chegar até aos 40 metros de altura (Pieri et al., 2009). Das 72 espécies descritas em todo o mundo pelo Index kewensis (Hooker e Jackson, 1895), 16 são exclusivas da flora brasileira. Da copaibeira extrai-se um óleo, denominado óleo de copaíba, rico em diterpenos e sesquiterpenos (Rigamonte Azevedo et al., 2004), e com inúmeras propriedades potenciais para uso na medicina, como sua ação antiinflamatória, antimicrobiana e antisséptica (Pieri et al., 2009). Essas características mostram-se desejáveis para um agente quimioterápico na prevenção e no tratamento da doença periodontal. Estudos recentes têm procurado comprovar tais atividades descritas em ensaios laboratoriais, porém ainda são poucos os estudos clínicos para conceder credibilidade a esse tipo de medicamento (Gilbert et al., 2002; Gurgel, 2004; Simões, 2004).

A proposta do presente estudo foi avaliar a ação de uma solução de óleo de copaíba como agente quimioterápico antimicrobiano oral em cães, comparando a redução da presença de placa bacteriana conferida por esta à redução provocada pelo digluconato de clorexidina e por outra solução, sem princípio ativo.

\section{MATERIAL E MÉTODOS}

A solução utilizada como controle negativo foi formulada com $30 \mathrm{~mL}$ de álcool a $96^{\circ}, 20 \mathrm{~mL}$ de propilenoglicol, $20 \mathrm{~mL}$ de polietilenoglicol, $20 \mathrm{~mL}$ de glicerina e $10 \mathrm{~mL}$ de água destilada. A solução teste era composta pela solução controle negativo acrescida de $10 \mathrm{~mL}$ de óleo de copaíba em substituição à água destilada. Para o controle positivo, a solução controle negativo foi acrescentada de clorexidina na concentração final de $0,12 \%$ do princípio ativo. 
Foram utilizados 18 cães sem raça definida, entre quatro e oito anos, com peso corporal entre oito e 20 quilos, que foram tratados com ração comercial e água ad libitum. Todo o processo experimental foi aprovado pelo Comitê de Ética em Pesquisa da UNIFENAS (Parecer $n^{\circ}$ 01.A/2007). Os animais foram distribuídos em três grupos, tratados três vezes ao dia, durante oito dias, com a solução apropriada, aplicada topicamente com o auxílio de pinça hemostática e gaze. Antes do início do estudo, foram feitas inspeções clínicas nos animais para avaliar a halitose presente e a gengivite; os parâmetros foram devidamente classificados de acordo com índices descritos por Culham e Rawlings (1998) e Clarke (2001) para a halitose, e por Roza (2004), para a gengivite. Essas inspeções foram repetidas todos os dias, antes da primeira aplicação diária das soluções. Ao fim do período de tratamento, todos os animais foram submetidos à evidenciação da placa bacteriana presente na superfície dental, por meio de uma coloração feita com solução de fucsina básica a $0,5 \%$, e fotografaram-se as faces vestibulares dos dentes com câmera digital. As imagens foram analisadas em pacote gráfico Imagelab 2.4 (Softium, Ceará, Brasil), e foram calculadas a área total dos dentes (ATD) e a área com evidenciação bacteriana revelada pela fucsina (AEB), dos dentes caninos, pré-molares e molares. Posteriormente, obteve-se o índice de placa presente (IPP) nos dentes analisados de cada animal, por meio da expressão: $I P P=(A E B$ /ATD) $\times 100$

Para todos os ensaios, foi utilizada a bactéria Streptococcus mutans (ATCC 25175), considerando sua importância na formação da placa bacteriana. Para o ensaio de antibiograma pela técnica do poço, foram adicionadas outras três cepas: Streptococcus salivarius (CDC 262), Streptococcus pyogenes (ATCC 19615) e Enterococcus faecalis (ATCC 19433).

Para o antibiograma, foram utilizadas placas de Petri de $9 \mathrm{~cm}$ de diâmetro contendo uma camada inferior com $20 \mathrm{~mL}$ de ágar bacteriológico $\mathrm{n}^{\circ} 1$ (Oxoid - Hampshire, UK), e, acima desta, outra com $30 \mathrm{~mL}$ de ágar infusão cérebro e coração (ágar BHI) (Acumedia, Neogen Corporation Lansing, EUA). Com o uso de tubos de Kahn, foram feitos três poços esféricos no ágar BHI equidistantes na placa. Utilizando-se as cepas de S.mutans, S. salivarius, S. pyogenes e E. faecalis em tubos contendo culturas puras, preparou-se um tubo para cada bactéria de uma suspensão microbiana em solução de cloreto de sódio(Merck Brasil - São Paulo, Brasil) a 0,9\% adequada à escala 0,5 de turbidez de McFarland. Os microrganismos foram inoculados em três placas cada, acrescentando-se, na superfície do ágar BHI, uma alíquota de $0,1 \mathrm{~mL}$ da suspensão microbiana, que foi semeada sobre a placa com o auxilio de alças de Drigalski. As placas foram incubadas em estufa a $35,5^{\circ} \mathrm{C}$ por $24 \mathrm{~h}$. A atividade antimicrobiana de cada solução foi representada na forma de halos de inibição, que foram medidos com paquímetro.

Foi realizado também um teste de inibição de aderência de $S$. mutans utilizando-se cinco tubos por tratamento, contendo meio de cultura caldo triptona soja (TSB)(Oxoide) adicionado de sacarose (Vetec - Rio de Janeiro, Brasil), para concentração final desta a $5 \%$ no meio. Nos tubos iniciais, o volume usado inicialmente foi de $10,8 \mathrm{~mL}$ do meio, e, nos demais tubos, $6 \mathrm{~mL}$. Acrescentou-se, então, nos respectivos tubos, $1,2 \mathrm{~mL}$ das soluções a serem testadas, perfazendo o volume de $12 \mathrm{~mL}$ nesses tubos. A partir daí, homogeneizou-se o meio com a solução e transferiram-se $6 \mathrm{~mL}$ para o tubo seguinte, repetindo o procedimento até o quinto tubo, de onde se retirou uma alíquota de $6 \mathrm{~mL}$ para que ficassem igualados os volumes dos tubos. Obtiveram-se, então, concentrações das soluções que variaram de $100 \mu \mathrm{l} / \mathrm{mL}$ do meio até $6,25 \mu \mathrm{l} / \mathrm{mL}$. Cada tubo foi contaminado por alíquota de $0,1 \mathrm{~mL}$ de uma suspensão de $S$. mutans em solução salina $0,9 \%$, com turbidez devidamente adequada à escala 1 de McFarland. Cada tubo recebeu uma bengala de vidro feita a partir de capilares de $75 \mathrm{~mm}$, com extremidades vedadas pelo fogo do bico de Bunsen, que também conferiu forma curva a uma das extremidades para conformação da bengala. $\mathrm{O}$ peso de cada bengala foi aferido em balança analítica. Os tubos foram incubados em estufa a $35,5^{\circ} \mathrm{C}$ por $48 \mathrm{~h}$. Passada a incubação inicial, cada bengala foi retirada de seu tubo, colocada em outro tubo que continha $6 \mathrm{~mL}$ de solução salina estéril, e agitada rigorosamente até a sua retirada da solução salina, quando foi colocada em tubo que continha $6 \mathrm{~mL}$ de meio de cultura TSB a 5\% de sacarose novo, e reincubada por mais 48 horas, nas mesmas condições da incubação inicial. Ao final do período, as bengalas foram analisadas visualmente por 
método subjetivo, descrito por Swerts et al. (2005), com a classificação (-) para a ausência de crescimento microbiano na bengala, (+) para crescimento não saliente e escasso, $(++)$ para crescimento não saliente e abundante, $(+++)$ para crescimento saliente e escasso e $(++++)$ para crescimento saliente e abundante.

Realizada a análise subjetiva, as bengalas foram retiradas e pesadas após sua secagem em câmara de fluxo estéril, subtraindo-se do resultado os pesos iniciais das bengalas, obtendo-se o peso de microrganismos aderidos a cada bengala.

Os resultados obtidos no ensaio in vivo, nas avaliações clínicas, foram analisados por testes não paramétricos. Para tanto, subtraiu-se o índice de avaliação inicial dos animais para cada parâmetro clínico (halitose e gengivite) do índice encontrado ao final do experimento. Utilizou-se o teste Kruskal-Wallis para comparação entre os três grupos, e o teste Dunn para comparações múltiplas pareadas, por meio do pacote estatístico Graphpad Instat, 3.01(GraphPad Software Inc., Califórnia, EUA).

Os dados obtidos pelo processamento das fotografias foram submetidos à análise de variância, satisfeitas as premissas do método, organizada em forma de um delineamento inteiramente ao acaso. Foi escolhido, para a análise estatística, o teste quantitativo TukeyKramer.

Os dados obtidos no antibiograma e no ensaio de inibição de aderência microbiana foram analisados de forma quantitativa, por meio de análise de variância balanceada com duas variáveis, utilizando-se para isso o software XLStatistics (Versão 5.0, Rodney Carr, Pensylvania, EUA).

Para todas as análises estatísticas, foi aceito nível de significância de $5 \%$.

\section{RESULTADOS}

No resultado do teste de evidenciação da placa bacteriana (média $\pm E P$ ) com solução de fucsina, a área de cobertura com placa foi de $22.4 \pm 5.3 \%$ para a solução teste com óleo de copaíba, de $29,2 \pm 5,4 \%$ para a solução controle positivo e de $54,6 \pm 8,8 \%$ de cobertura para a solução controle negativo. Não houve diferença estatística entre a solução de óleo de copaíba e a de controle positivo, e observou-se diferença significativa entre esses grupos e o grupo controle negativo $(\mathrm{P}<0,001)$.

Os escores de melhora clínica dos animais estão apresentados na Tab. 1. O teste Kruskal-Wallis mostrou, para todos os critérios clínicos avaliados, que houve semelhança entre os grupos teste e controle positivo, cujos resultados foram mais altos e diferentes do grupo controle negativo $(\mathrm{P}<0,02)$. Para o sinal clínico halitose, o teste Dunn de comparação múltipla reconheceu diferença apenas na comparação entre a solução de copaíba e a solução de controle negativo, considerando iguais estatisticamente o controle negativo e a solução controle positivo, e essa em relação à copaíba. Quanto à mudança percebida no grau de gengivite dos animais, o resultado do teste Dunn apresentou diferença significativa nas comparações do controle negativo com as outras duas soluções $(\mathrm{P}<0,01)$, enquanto as soluções de copaíba e controle positivo apresentaram resultados iguais $(\mathrm{P}>0,05)$.

Todos os microrganismos utilizados neste ensaio mostraram-se resistentes à solução controle negativo, sem princípio ativo, pois não apresentaram halo de inibição em nenhuma placa. Para análise estatística, foram utilizados os dados obtidos com os halos medidos nas demais soluções. A análise de variância indicou diferença entre os tratamentos $(\mathrm{P}<0,05)$. Para a solução de copaíba, a média foi de $30,5 \mathrm{~mm}$, e, para a solução controle positivo, $27,1 \mathrm{~mm}$ no halo de inibição dos microrganismos. A mesma análise apontou, ainda, diferença na suscetibilidade à inibição de crescimento pelas substâncias entre os microrganismos testados ( $\mathrm{P}<0,001)$. S. pyogenes foi o mais susceptível, média de halo de inibição de $38,8 \mathrm{~mm}$, contra $25,8 \mathrm{~mm}, 24,5 \mathrm{~mm}$ e $26,2 \mathrm{~mm}$ de S.mutans, $S$. salivarius e E. faecallis, respectivamente.

Por meio da análise de variância balanceada do peso da placa bacteriana aderida nas bengalas (Fig. 1), os resultados apontaram diferenças $(\mathrm{P}<0,002)$ entre a solução de copaíba, média de $134 \mu \mathrm{g}$ de placa aderida, e a solução controle positivo, $309 \mu \mathrm{g}$ de média, e entre aquela e a solução controle negativo, com $340 \mu \mathrm{g}$ de peso médio de placa aderida. Entre as soluções controle positivo e controle negativo, não houve diferença $(P>0,05)$. Com relação às diferentes 
diluições, não ocorreu diferença significativa entre as concentrações utilizadas no ensaio $(\mathrm{P}>0,05)$. A inspeção e a classificação visual das bengalas confirmaram os resultados obtidos com os pesos, apontando para a solução de copaíba bengala sem aderência (-) e com aderência com crescimento escasso e não saliente $(+)$; para o controle positivo, bengalas com crescimento saliente, escasso (+++) ou abundante (++++), com exceção do tubo com maior concentração, que apresentou apenas crescimento escasso e não saliente (+); e para a solução controle negativo, bengalas com crescimento saliente e abundante $(++++)$. Para ambas as análises feitas neste ensaio, os tubos que continham apenas o meio contaminado, sem tratamento, apresentaram resultados semelhantes aos do controle negativo, com crescimento abundante e saliente (++++), com média de aderência de $443 \mu \mathrm{g}$ da bactéria.

Tabela 1. Escores de melhora clínica estabelecidos pela subtração do escore inicial e final dos aspectos clínicos de cães para cada tratamento

\begin{tabular}{lccc}
\hline Cães & Halitose & Placa & Gengivite \\
\hline Copaíba 1 & 1 & 2 & 1 \\
Copaíba 2 & 2 & 2 & 2 \\
Copaíba 3 & 2 & 3 & 3 \\
Copaíba 4 & 1 & 2 & 1 \\
Copaíba 5 & 1 & 1 & 1 \\
Copaíba 6 & 2 & 1 & 3 \\
Clorexidina 1 & 2 & 2 & 1 \\
Clorexidina 2 & 1 & 2 & 3 \\
Clorexidina 3 & 1 & 1 & 2 \\
Clorexidina 4 & 2 & 1 & 1 \\
Clorexidina 5 & 1 & 1 & 1 \\
Clorexidina 6 & 1 & 3 & 1 \\
Placebo 1 & 1 & 1 & -1 \\
Placebo 2 & 1 & 0 & -1 \\
Placebo 3 & 0 & 0 & 0 \\
Placebo 4 & 0 & 0 & -1 \\
Placebo 5 & 0 & 1 & 1 \\
Placebo 6 & 0 & 1 & -1 \\
\hline
\end{tabular}

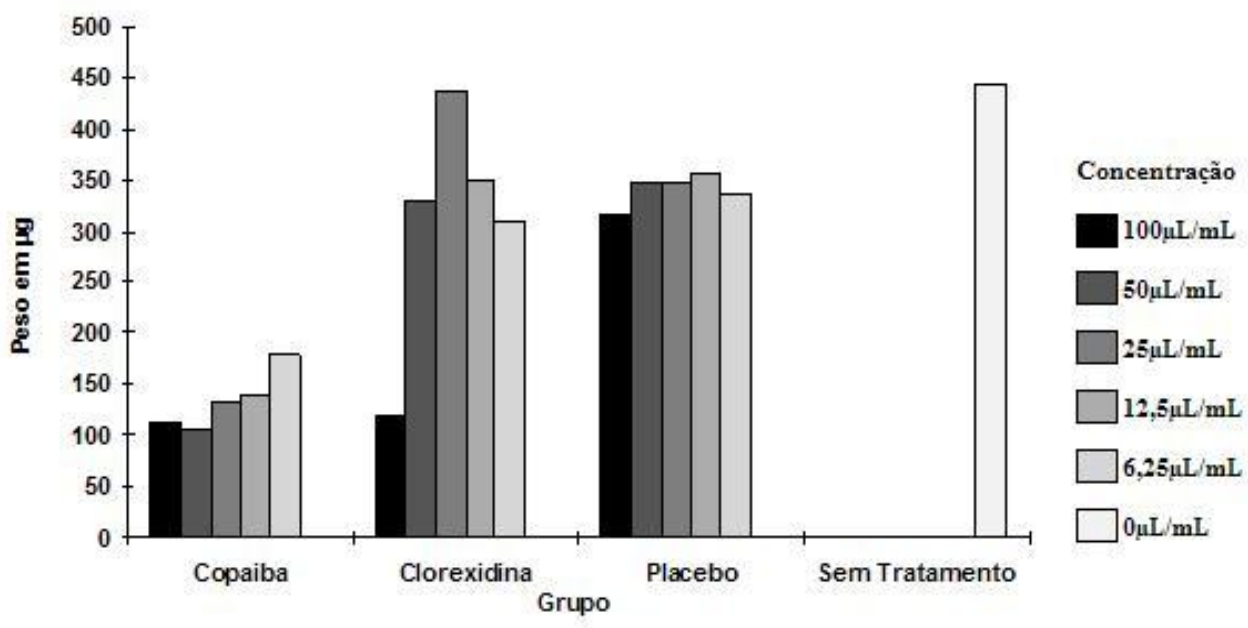

Figura 1. Peso dos microrganismos $(\mu \mathrm{g})$ aderidos às bengalas feitas com capilar de vidro, para cada diluição e tratamento. 


\section{DISCUSSÃO}

A doença periodontal é a patologia com maior acometimento dos cães e apresenta como agente etiológico a placa bacteriana (De Marco e Gioso, 1997; Brown e McGenity, 2005). Para a eficaz instalação de processo patológico, há necessidade de uma boa aderência dos microrganismos à superfície em questão e crescimento bacteriano (Corner et al., 1988). Dessa forma, o combate às bactérias colonizadoras iniciais e formadoras da placa, pela interferência na aderência e no crescimento microbiano, reverte-se em eficaz terapia preventiva à doença periodontal.

O óleo de copaíba tem sido testado quanto à sua atividade antimicrobiana sobre as bactérias formadoras da placa dental, com bons resultados in vitro, porém sem realização de testes em modelos in vivo, o que poderia conceder credibilidade ao uso clínico do medicamento (Gilbert et al., 2002; Gurgel, 2004; Simões, 2004). A solução de óleo de copaíba, no presente trabalho, apresentou resultados significativamente positivos comparados aos do controle negativo, apresentando médias de inibição bacteriana in vitro e in vivo mais altas. Quando aquela foi comparada ao controle positivo, os resultados não apresentaram diferença significativa para a maioria dos ensaios, com exceção da atividade inibitória da aderência de $S$. mutans, no qual a solução de copaíba foi considerada superior.

Semelhante a outros estudos antimicrobianos in vitro que utilizaram o óleo de copaíba contra bactérias da placa dental (Gilbert et al., 2002; Gurgel, 2004; Simões, 2004), este estudo mostrou atividade antimicrobiana in vitro pela solução de copaíba sobre os microrganismos orais $S$. mutans, S. salivarius, S. pyogenes e $E$. faecalis. Os halos de inibição foram maiores que os obtidos com o controle positivo $(\mathrm{P}<0,05)$. Tal resultado confirma a ação inibitória microbiana, levantada pelo trabalho de Bloise (2003), que cita a ação germicida de um dos componentes do óleo de copaíba, o $\beta$-cariophileno. Com relação à cepa $S$. pyogenes, Gonçalves et al. (2005), em um ensaio de difusão em ágar, utilizaram extrato da casca da copaibeira, o qual não inibiu o crescimento do microrganismo. Sugere-se, assim, que a atividade inibitória sobre a referida bactéria é praticada por componente presente apenas no óleo de copaíba, e não na casca da árvore.

Quanto à atividade inibitória de aderência microbiana, característica desejável a uma solução oral antiplaca, o óleo de copaíba apresentou resultados melhores que as demais soluções no ensaio in vitro, fato constatado tanto por inspeção visual quanto pela análise quantitativa dos pesos das bengalas de vidro. Dessa maneira, pode-se atribuir parte da ação antimicrobiana da solução de copaíba a essa característica.

No controle positivo, porém, em todas as concentrações testadas, a atividade antiaderente foi considerada não significativa e semelhante à do controle negativo. Swerts et al. (2005) revelaram inibição da aderência de $S$. mutans pela clorexidina. Tal diferença entre os trabalhos pode ter ocorrido pelo uso de meios de cultura diferentes, pois, enquanto esses pesquisadores utilizaram um meio de cultura quimicamente definido, o presente trabalho utilizou TSB acrescido de sacarose, seguindo o protocolo utilizado por Corner et al. (1988).

A solução controle negativo não apresentou nenhuma ação inibitória, em nenhum dos ensaios citados, indicando que as atividades descritas para as demais soluções se deviam aos princípios ativos adicionados.

Conforme suposto a partir dos testes de ação antimicrobiana in vitro, e da literatura referente à ação do óleo de copaíba como antibacteriano (Pieri et al., 2009), houve inibição da formação da placa bacteriana dental nos cães pela solução com óleo de copaíba, revelada pela redução significativa na formação bacteriana na área dos dentes analisados. Como o resultado foi considerado semelhante ao do controle positivo, que continha a solução de clorexidina $0,12 \%$, tratamento utilizado na rotina clínica, sugere-se a substituição deste pela solução de copaíba, após estudos que verifiquem a ausência de efeitos colaterais ou que estes se apresentem mais brandos quando comparados à clorexidina.

Deve-se ressaltar que, por ser uma substância composta, o óleo de copaíba pode apresentar até 72 compostos sesquiterpênicos diferentes e até 26 diterpênicos (Pieri et al., 2009). Isto poderia inibir a formação de bactérias resistentes durante 
o seu uso prolongado, pois várias dessas substâncias podem apresentar mecanismos inibitórios diferentes sobre a célula bacteriana. Além disso, sugere-se que a atividade de inibição da aderência poderia ocorrer devido a uma substância diferente das que possuem ação inibitória do metabolismo reprodutivo bacteriano.

\section{CONCLUSÕES}

O óleo de copaíba, pelas atividades antimicrobiana e inibitória da aderência sobre bactérias formadoras de placa dental em cães, surge como um candidato a substituir a clorexidina na terapia antimicrobiana oral, com a possível vantagem de dificultar o surgimento de bactérias resistentes. Por isso, futuramente o óleo de copaíba poderia ser utilizado como um quimioterápico preventivo à doença periodontal, de uso prolongado, desde que em estudos complementares comprove-se essa vantagem e a ausência de efeitos colaterais.

\section{AGRADECIMENTO}

À FAPEMIG, pelo suporte financeiro.

\section{REFERÊNCIAS BIBLIOGRÁFICAS}

BLOISE, M.I. Óleos vegetais e especialidades da floresta amazônica. Cosmetics Toiletries, v.15, p.46-49, 2003.

BROWN, W.Y; McGENITY, P. Effective periodontal disease control using dental hygiene chews. J. Vet. Dent., v.22, p.16-20, 2005.

CLARKE, D.E. Clinical and microbiological effects of oral zinc ascorbate gel in dogs. J. Vet. Dent., v.18, p.177-183, 2001.

CORNER, A.M.; DOLAN, M.M.; YANKELL, S.L. et al. C31G, a new agent for oral use with potent antimicrobial and antiadherence properties. Antimicrob. Agent Chemoth., v.32, p.350-353, 1988.

CULHAM, N.; RAWLINGS, J.M. Oral malodor and its relevance to periodontal disease in the dog. J. Vet. Dent., v.15, p.165-168, 1998.

DE MARCO, V.; GIOSO, M.A. Doença periodontal em cães e gatos: profilaxia e manejo dietético. Rev. Clin. Vet., v.2, p.24-28, 1997.
GILBERT, B.; ALVES, L.; FERREIRA, J.L. A base científica da fitoterapia. Cienc. Ambiente, v.25, p.129-135, 2002.

GIOSO, M.A. Odontologia para o clínico de pequenos animais. São Paulo: iEditora, 2003. 202 p.

GONÇALVES, A.L.; ALVES FILHO, A.; MENEZES, M. Estudo comparativo da atividade antimicrobiana de extratos de algumas árvores nativas. Arq. Inst. Biol., v.72, p.353-358, 2005.

GURGEL, C.B. A fitoterapia indígena do Brasil colonial (os primeiros dois séculos). In: ENCONTRO REGIONAL DE HISTÓRIA, 11., Rio de Janeiro, 2004. Disponível em: <http://www.uff.br/ichf/anpuhrio/Anais/2004/ind ice2004.htm>. Acessado em: 24 fev. 2007.

HARVEY, C.E.; THORNSBERRY, C.; MILLER, B.R. et al. Antimicrobial susceptibility of subgingival bacterial flora in dogs with gingivitis. J. Vet. Dent., v.12, p.51-55, 1995.

HENNET, P. Effectiveness of a dental gel to reduce plaque in beagle dogs. J. Vet. Dent., v.19, p.11-14, 2002.

HOOKER, J.D.; JACKSON, B.D. Index Kewensis Plantarum Phanerogamarum nomina et Synonyma Omnium generum et specierum a Linnaeo usq. Oxford: The Clarendon Press, 1895.

KATSURA, H.; TSUKIYAMA, R.I.; SUZUKI, A.; KOBAYASHI, M. In vitro antimicrobial activities of bakuchiol against oral microorganisms. Antimicrob. Agent Chemoth., v.45, p.3009-3013, 2001.

LASCALA, N.T.; MOUSSALLI, N.H. Compêndio terapêutico periodontal. 2.ed. São Paulo: Artes Médicas, 1995. 263p.

PIERI, F.A.; MUSSI, M.C.M.; MOREIRA, M.A.S. Óleo de copaiba (Copaifera sp.): histórico, extração, aplicações industriais e propriedades medicinais. Rev. Bras. Plant. Med., v.11, p.465-472, 2009.

RIGAMONTE AZEVEDO, O.C.; WADT, P.G; WADT, L.H. Copaíba: ecologia e produção de óleo-resina. Rio Branco: Embrapa Acre, 2004. $28 \mathrm{p}$.

ROZA, M.R. Odontologia em pequenos animais. Rio de Janeiro: L.F. Livros de Veterinária, 2004. 361p. 
SANS, M.; NEWMAN, M.G. Placa dental e cálculo. In: NISENGARD, R.J.; NEWMAN, M.G. (Eds). Microbiologia oral e imunologia. 2.ed. Rio de Janeiro: Guanabara Koogan, 1997. p.275-292.

SIMÕES, C.A.C.G. Patente $n^{\circ}$ PI0404266-2. Rio de janeiro: Instituto Nacional de Propriedade Industrial, 2004.

SUDO, S.Z.; SCHOTZKO, N.K.; FLOKE, L.E. Use of hydroxyapatite-coated glass beads for preclinical testing of potential antiplaque agents. Appl. Env. Microbiol., v.32, p.428-432, 1976.
SWERTS, M.S.; COSTA, A.M.; FIORINI, J.E. Efeito da solução associada de clorexidina e própolis na inibição da aderência de Streptococcus spp. Rev. Int. Periodont. Clín., v.2, p.10-16, 2005.

ZANINI, A.C.; BASILE, A.C.; MARTIN, M.I. et al. Guia de medicamentos. São Paulo: Atheneu, 1995. 787p. 